\title{
ENVIRONMENTAL RECOVERY TRAINING FOR BIOLOGICAL INCIDENTS: IMPRESSIONS FROM PHARMACY STUDENTS
}

\author{
A. Peña-Fernández ${ }^{1}$, M.A. Peña ${ }^{2}$, M.D. Ollero ${ }^{3}$, C. Hurtado ${ }^{3}$, S. Fenoy ${ }^{3}$ \\ ${ }^{1}$ Faculty of Health and Life Sciences, De Montfort University, The Gateway \\ (UNITED KINGDOM) \\ ${ }^{2}$ Unidad de Farmacia y Tecnología Farmacéutica, Departamento de Ciencias Biomédicas \\ Universidad de Alcalá (SPAIN) \\ ${ }^{2}$ Facultad de Farmacia, Universidad San Pablo CEU (SPAIN)
}

\begin{abstract}
An innovative teaching group at De Montfort University (DMU, UK) and at the University of Alcalá (Spain) has developed specific training to prepare human health students to respond to biological incidents. The purpose of this training is to provide a basic understanding of environmental toxicology, recovery, public health and medical preparedness to protect humans and minimise the spread of biological hazards. We have followed previous experience gained when responding to the 2014-16 Ebola outbreak in Makeni, Sierra Leone (West Africa). Previously, to create this training, a series of basic competences to respond to biological incidents were created by our group for undergraduate students [1] following the European Commission competences specified for medical responders [2]. A critical part of any intervention plan to respond to these incidents is to implement a quick response to protect the public and actions to minimise the occurrence of infections and recover the environment affected by the biological agent(s) since they can subsequently impact humans. A specific short training course/workshop ( 3 hours long) has been created in conjunction with a series of specific lectures on emerging pathogens, biological hazards and prevention, medical preparedness and public health. Students were provided with a biological incident scenario affecting different environments (open water and food production systems) and they needed to tailor a basic recovery strategy following the novel methodology and guidelines to tailor a recovery response to biological incidents developed by Public Health England (PHE) [3]. Our recovery training has been tested within different undergraduate and postgraduate programmes (BSc Biomedical and BMedSci Medical Science; MSc Advances in Biomedical Science) at DMU during the 2016/17 academic course; we have determined high levels of student satisfaction and engagement. Currently we are in the process of validating this training by delivering it in other European universities and/or different health care programmes. Thus, we delivered a modified version of this recovery training/workshop to third year pharmacy students $(n=101)$ enrolled in the module Biological Analysis \& Laboratory Diagnostic at the Universidad de San Pablo CEU (Spain) in April 2017. Pharmacy students gain an appropriate knowledge on infectious diseases, microbiology and parasitology during the first two years of study, so we decided to reduce the length of the workshop to 1.5 hours. A validated feedback-questionnaire was distributed that has revealed the following initial impressions (33 students completed the questionnaire): $93.9 \%$ of students enjoyed the different exercises created ( $45.4 \%$ agreed; $48.5 \%$ strongly agreed); only $6.1 \%$ of them did not $(6.1 \%$ disagreed; $0 \%$ strongly disagreed). $87.9 \%$ of these students reported that the novel PHE resources used aided their learning on environmental recovery and restoration. Finally, $93.9 \%$ of students $(42.4 \%$ agreed; $51.5 \%$ strongly agreed) indicated that they have gained knowledge to tailor a basic recovery plan in the aftermath of a biological incident; $6.1 \%$ disagreed. These results should be considered as preliminary and the training was shown to be successful in facilitating health care students to acquire basic skills to recover environments affected by future biological incidents and outbreaks of infection.
\end{abstract}

Keywords: Pharmacy undergraduate students, biological incidents training, public health, environmental recovery and restoration.

\section{INTRODUCTION}

Biological incidents and outbreaks of infection are natural, accidental or deliberate (bioterrorism) events that involve the release and spread of biological agents or hazards [4]. Large scale biological incidents can present an enormous challenge to the health care system. These events require highly skilled first responders and an appropriate and quick response to protect the public $[5,6]$. Thus, the unprecedented 2014-2016 Ebola epidemic in West Africa highlighted the relevance of implementing 
applicable, effective, well-coordinated and quick international intervention responses to reduce the spread of the Ebola virus and protect human health [7]. These large scale biological incidents are not frequent, but when they occur can potentially affect several countries. Recent examples affecting the European Union (EU) are the foodborne outbreaks related to different species of Shiga-toxinproducing Escherichia coli infection in Germany [8]. These events have demonstrated that rapid identification of the biological hazard is critical to developing appropriate medical intervention and infection containment strategies [9].

Moreover, there is an increasing threat of using biological hazards or agents in unconventional weapons, which could result in a high number of casualties and socio-economic impact. Therefore, the European Union (EU) Council has developed a Chemical, Biological, Radiological and Nuclear (CBRN) action plan that focuses on prevention, detection, preparedness and response [10].

Environmental and mass casualty decontamination in the aftermath of a biological incident is one of the main interventions to protect human health and minimise the spread of a biological hazard [11]. Owing to the fact that biological agents spread easily and the likelihood of developing environmentally resistant forms [12] such as spores (e.g. anthrax) [13], any biological incident intervention response should consider appropriate measures to decontaminate and restore the affected environment(s) to protect the public. Biological agents can contaminate various environmental compartments such as air, water, food, soil, and fomites, so appropriate and validated monitoring should be carried out to develop the most applicable recovery strategy [3,14]. Novel guidance and advice to facilitate the decontamination and restoration of an environment following a biological incident or outbreak of infection has been developed within the UK in the "UK Recovery Handbook for Biological Incidents" (UKRHBI) $[3,15]$. However, an EU or global standardised approach for remediating the environment would be useful.

Future health care professionals will need to be able to deal with biological incidents and outbreaks of infection but very little training is provided in human health degree programmes in Europe to face future crises [16]. Djalali et al. (2016) [2] have recently described that this training would be especially insufficient amongst clinicians and other health professionals despite their critical role as part the initial response to an incident.

\subsection{Biological incident response training}

In order to fill this gap in the curricula, an innovative teaching group at De Montfort University (DMU, Leicester, UK) and at the University of Alcalá (UAH, Spain), in collaboration with first responders (biomedical scientists) during the 2014-16 Ebola outbreak in Sierra Leone [17], are developing training for undergraduate human health degree students to respond to biological and chemical incidents. We have initially developed basic competences to develop this training and distributed them into six domains [18]: identification of the risk and risk analysis; toxicological effect of biological agents; planning and organisation of an intervention programme; environmental planning; communication and information management; safety and personal protective equipment; societal and ethical reflections. Our basic competences are based on the core competences identified by the European Commission for medical responders to CBRN emergencies [2]. To increase the robustness of our basic competences so they reflect the knowledge, abilities and skills required by future health professionals to respond to biological incidents or outbreaks of infection, we will seek analysis and comments from experts from other universities and organisations.

Since 2015/16 we have been creating different training sessions with two components, theoretical (lectures and seminars) and practical (research-led workshop), to cover each of the different phases of a biological incident response [19]: preparedness and situation assessment; exposure assessment; acute health effects; long term health effects; and recovery phase. More information about some of these teaching sessions can be found elsewhere [16-18]. These training sessions have been distributed and introduced in a range of undergraduate and postgraduate programmes at DMU in 2016/17 according to allocated time (i.e. space), background and skills of students, and the main programme objectives: BSc Biomedical Science and BMedSci Medical Science degree programmes, and the MSc. in Advanced Biomedical Science. Preliminary analysis of the feedback provided by DMU students indicated high levels of engagement and interest in these training sessions (data not published). The purpose of this work is twofold: a) to assess the effectiveness of the specialised training session that covers the recovery phase, which was initially tested with MSc students at DMU, in facilitating the specific basic competences covered in this training; and b) to gain feedback on the use of the UKRHBI as a possible teaching resource. To meet these objectives, we have simplified this specialised training to deliver it to pharmacy students at the University of San Pablo CEU (USP-CEU). 


\section{METHODOLOGY}

Our study was carried out in April 2017 at USP-CEU (second term). To meet our objectives, we have simplified this specialised training to deliver it to pharmacy students studying the Bachelor's Degree in Pharmacy programme (300 ETCS) at the University of San Pablo CEU (USP-CEU). The curriculum of this programme can be found here: http://www.uspceu.com/es/oferta-academica/grado/04farmacia/index.aspx

The training was prepared and delivered by a DMU academic as part of an Erasmus+ staff mobility grant for teaching $(2016 / 17$ scheme) to third year students $(n=101)$ enrolled in the compulsory module of Biological Analysis \& Laboratory Diagnostic (6 ETCS) [20]. Erasmus teaching staff mobility has been reported as a relevant tool to improve internationalisation and in the development of teaching methods and as a resource to strengthen curricula development [21]. We have used this staff mobility grant to determine the effectiveness of our novel training in a human health degree programme other than Medical or Biomedical Sciences and in a non-English European university.

The original training or research-led workshop created at DMU was simplified to 1.5 hours' length. Students were required to develop a basic recovery and restoration plan to protect human health and contain the infection in the aftermath of an outbreak of infection produced by Cyclospora cayetanensis in an urban environment. We selected this protozoan parasite as it has been described as a Category B Priority Pathogen by the National Institute of Allergy and Infectious Diseases (NIAID) [22]. The NIAID Emerging Infectious Diseases/Pathogens category includes Biodefense Research and Additional Emerging Infectious Diseases/Pathogens which determine different ranges of threat. Moreover, we have also selected this parasite as the biological agent to overcome time constraints as these pharmacy students have already studied parasitology in the first term [23]. Students were provided with a case scenario to tailor a recovery and restoration plan using some of the resources available in the novel methodology developed by Public Health England in the UKRHBI [3]. The UKRHBI provides a series of recovery options to decontaminate different environments impacted by biological hazards, which are selected/rejected according to the physiological characteristic of the organism and the characteristics of the site $[3,15]$. Students, working in teams, were able to select applicable/reject non-effective options by using critical analysis and reflection on previous knowledge (e.g. the life cycle of Cyclospora). Thus, for example, recovery options that use decontamination liquids such as chlorine will have a limited efficiency as oocysts of Cyclospora are resistant to this chemical and therefore should be not considered in the recovery plan. Prior to tailoring their response, students were provided with a very brief session on Cyclospora and how to use the food production system section of the UKRHBI [3]. Additionally, students were provided with a small workbook with the necessary information to complete the case scenario proposed (including the physiological characteristics of Cyclospora).

Groups showed their intervention programme to the classroom by selecting a "presenter". Each presenter provided a rationale for accepting/rejecting each recovery option for the proposed scenario. During this part of the training session, active participation and reasoning were sought from students by formulating questions. Finally, all students participated in selecting the most effective intervention for the scenario, responses that were used to identify the level of understanding of the workshop. This methodology was useful to clarify erroneous knowledge or misinformation.

To analyse this teaching experience, comprehensive feedback was collected using the same validated feedback-questionnaires developed by our team and used with DMU students. Peña-Fernández et al. (2015) [24] have described that questionnaires can measure the degree of satisfaction of the teaching and learning processes. This questionnaire contains different questions using the Likert scale (strongly disagree, disagree, neither agree nor disagree, agree, strongly agree) and open-questions (freeresponse). Ethical approval was provided by the Research Ethics Committee at DMU (Ref. 1729) and from the Ethics Committee at the USP-CEU (Ref. 143/17/01).

\section{RESULTS AND DISCUSSION}

The voluntary feedback-questionnaire was completed by only 33 out of the 101 students appropriately (32.7\% response rate), only these questionnaires were used in this article. Questionnaires that were only partially completed were discarded.

The research-led workshop or training was well-received by USP-CEU pharmacy students, as evidenced by their favourable evaluation. Figure 1 shows that $93.9 \%$ of students enjoyed the different exercises created ( $45.4 \%$ agreed; $48.5 \%$ strongly agreed); only $6.1 \%$ of them did not $(6.1 \%$ disagreed; 
$0 \%$ strongly disagreed). This could be attributed to the novelty of the teaching session and the resources used. This result is in agreement with the preliminary results observed in the DMU MSc students which performed a similar workshop (approx. $78 \%$ enjoyed the different exercises delivered; data not published).

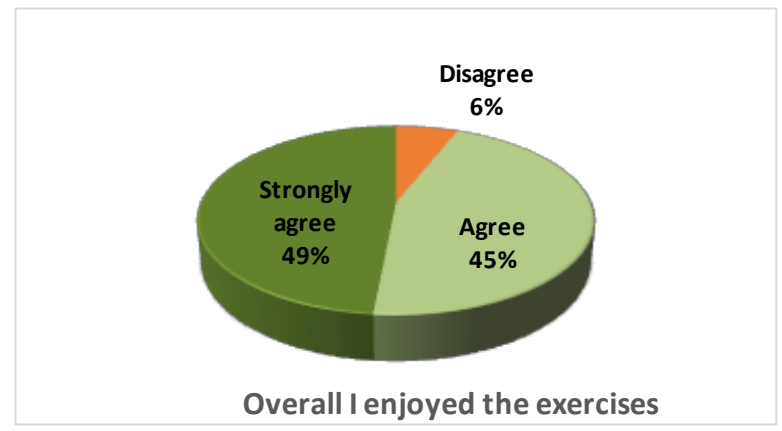

Figure 1. Student enjoyment (\%). Absence of a Likert category indicates no responses for that category.

In relation to the learning process and performance during the workshop, $87.9 \%$ of participants (Figure 2; 54.5 strongly agreed; $33.4 \%$ agreed) reported that the novel PHE resources (Pottage et al., 2015) used during the training aided their learning on environmental recovery and restoration. Students also were able to tailor an applicable recovery response, as shown during the discussion part of the training session. This observation has been also highlighted by the students in the feedbackquestionnaire provided. Thus, $93.9 \%$ of students $(42.4 \%$ agreed; $51.5 \%$ strongly agreed) indicated that they had gained knowledge to tailor a basic recovery plan in the aftermath of a biological incident; $6.1 \%$ disagreed (Figure 3 ).

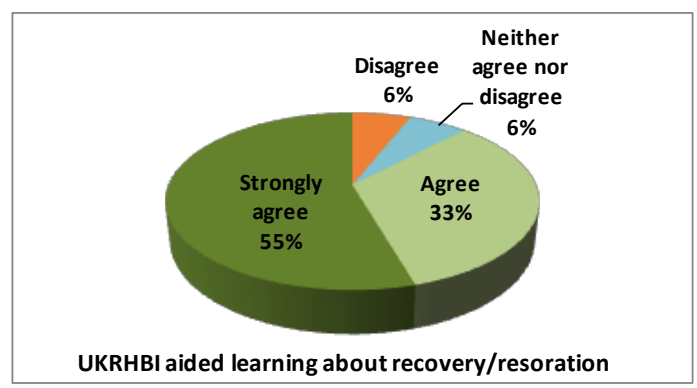

Figure 2. Students' opinion on the PHE tool (\%). Absence of a Likert category indicates no responses for that category.

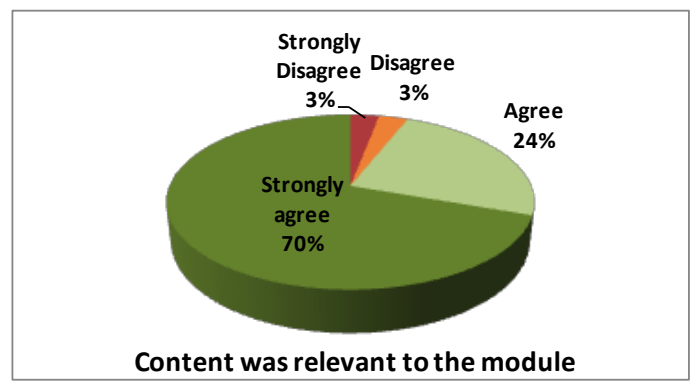

Figure 4. Students' opinion on the content of the training in their course (\%). Absence of a Likert category indicates no responses for that category.

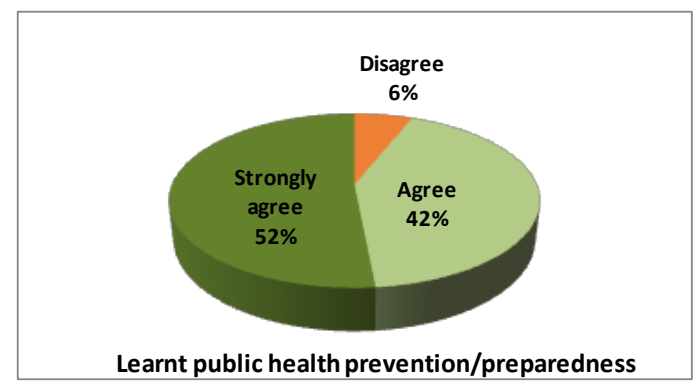

Figure 3. Students' learning (\%). Absence of a Likert category indicates no responses for that category.

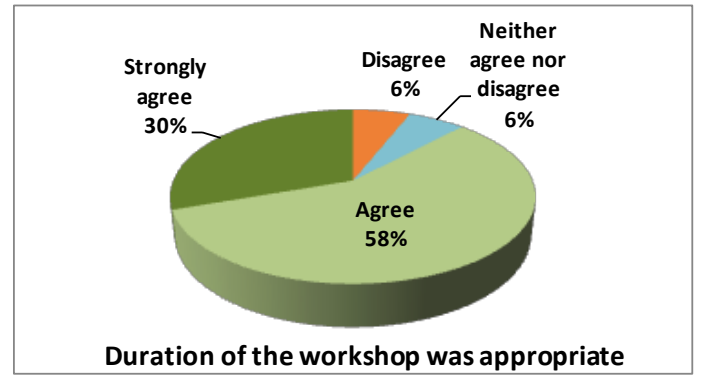

Figure 5. Students' opinion on the duration of the training (\%). Absence of a Likert category indicates no responses for that category.

Finally, 93.9\% of participants highlighted that the content learnt in the training was relevant to their programme (Figure 4); and $87.9 \%$ of them found the duration of the training as appropriate (Figure 5 ). The small percentage of students that indicated that the length of the workshop was not appropriate 
(6.1\%; Figure 5) could be attributed to the short time provided to complete the case scenario (1.5 hours). Thus, students have indicated in the open-questions that they would have liked a 2 hoursession or two workshops instead of one.

\section{CONCLUSIONS}

The analysis of the results so far, although they should be considered as preliminary, has demonstrated that the training, although limited in time, was effective in facilitating the acquisition of some of the basic competences/skills required by future health care professionals to respond to biological incidents developed by our group. Moreover, the training described could also facilitate the acquisition of relevant transversal competences for pharmacy students such as critical thinking, research skills (e.g. analysing and understanding research information), communication and team work.

\section{ACKNOWLEDGEMENTS}

The authors would like to thank the Erasmus+ staff mobility funds granted (2016-17) to Dr. PeñaFernández.

\section{DISCLAIMER}

The views in this article are those of the authors, not Public Health England.

\section{REFERENCES}

[1] Peña-Fernández A., Dunford LJ., Haris PI., Lobo-Bedmar MC., Peña MA. Harmonising the training of students within the EU to implement intervention programmes to protect the public in the aftermath of a HazMat incident. ICERI2016 Proceedings; pp. 3559-3565.

[2] Djalali A., Della Corte F., Segond F., Metzger MH., et al. TIER competency-based training course for the first receivers of CBRN casualties: a European perspective. Eur J Emerg Med. 2016; DOI: 10.1097/MEJ.0000000000000383.

[3] Pottage T., Goode E, Shieber C., Wyke S., Speight S., Bennett AM. UK Recovery Handbook for Biological Incidents 2015. PHE publications gateway number 2015406. Available at: https://www.gov.uk/government/publications/uk-recovery-handbook-for-biological-incidents [accessed 18/05/2017]

[4] Brown, N., Crawford, I., Carley, S., Mackway-Jones, K. (2006). A Delphi-based consensus study into planning for biological incidents. Journal of Public Health (Oxf), 28(3), 238-41.

[5] Ebadi, A., Yousefi, S., Khaghanizade, M., Saeid, Y. (2015). Assessment competency of nurses in biological incidents. Trauma Monthly, 20(4), e25607.

[6] Lansdowne, K., Scully, C.G., Galeotti, L., Schwartz, S., Marcozzi, D., Strauss, D.G. (2015). Recent advances in medical device triage technologies for chemical, biological, radiological, and nuclear events. Prehospital and Disaster Medicine, 30(3), 320-3.

[7] Bell, B.P., Damon, I.K., Jernigan, D.B., Kenyon, T.A., Nichol, S.T., O'Connor, J.P., Tappero, J.W. (2016). Overview, control strategies, and lessons learned in the CDC response to the 2014-2016 Ebola epidemic. Morbidity and Mortality Weekly Report (MMWR) Suppl., 65(3), 4-11.

[8] Frank, C., Milde-Busch, A., Werber, D. (2014). Results of surveillance for infections with Shiga toxin-producing Escherichia coli (STEC) of serotype O104:H4 after the large outbreak in Germany, July to December 2011. Euro Surveillance, 19(14), 1-6.

[9] Mölsä M, Hemmilä H, Katz A, Niemimaa J, Forbes KM, Huitu O, Stuart P, Henttonen H, Nikkari S. Monitoring biothreat agents (Francisella tularensis, Bacillus anthracis and Yersinia pestis) with a portable real-time PCR instrument. J Microbiol Methods 2015; 115:89-93. 
[10] Commission of the European Communities. Communication from the Commission to the European Parliament and the Council on Strengthening Chemical, Biological, Radiological and Nuclear Security in the European Union - an EU CBRN Action Plan. Brussels; 2009. Available at: https://ec.europa.eu/home-affairs/what-we-do/policies/crisis-and-terrorism/securingdangerous-material_en [accessed 18/05/2017]

[11] Power S, Symons C, Carter H, Jones E, Amlôt R, Larner J, Matar H, Chilcott RP. Mass casualty decontamination in the United States: an online survey of current practice. Health Secur 2016; 14(4):226-36.

[12] Sinclair R, Boone SA, Greenberg D, Keim P, Gerba CP. Persistence of category A select agents in the environment. Appl Environ Microbiol 2008; 74(3):555-63.

[13] D'Amelio E, Gentile B, Lista F, D'Amelio R. Historical evolution of human anthrax from occupational disease to potentially global threat as bioweapon. Environ Int. 2015; 85:133-46.

[14] Bresnitz EA. Indoor anthrax decontamination: how clean is clean? J Public Health Manag Pract 2010; 16:185-8.

[15] Pottage T., Goode E., Wyke S., Bennett AM. Responding to biological incidents - what are the current issues in remediation of the contaminated environment? Environ Int 2014; 72:133-9.

[16] Peña-Fernández A., Zinsky R., Choi E., Broadbent AJ. Developing training to prepare human health science students to face biological incidents. INTED2017 Proceedings 2017; pp. 47074714.

[17] Peña-Fernández A., Choi EML. Novel methods of teaching evidence-based medicine and public health: experience from the field during the Ebola outbreak. ICERI2016 Proceedings; pp. 43274335.

[18] Peña-Fernández A., Dunford LJ., Haris PI., Lobo-Bedmar MC., Peña MA. Harmonising the training of students within the EU to implement intervention programmes to protect the public in the aftermath of a HazMat incident. ICERI2016 Proceedings; pp. 3559-3565.

[19] Sandström BE, Eriksson H, Norlander L, Thorstensson M, Cassel G. Training of public health personnel in handling CBRN emergencies: a table-top exercise card concept. Environ Int. 2014; 72:164-9.

[20] Syllabus Biological Analysis \& Laboratory Diagnostic module. Available at the USP-CEU website: http://www.uspceu.com/_docs/oferta-academica/fac_far/farmacia/guias-docentes/GD5-a311-Analisis-Biologicos-y-Diagnostico-de-Laboratorio.pdf [accessed 18/05/2017]

[21] The Erasmus Impact Study. Publications Office of the European Union, 2014. ISBN: 978-92-7938380-9. Available at:

http://ec.europa.eu/dgs/education_culture/repository/education/library/study/2014/erasmusimpact_en.pdf [accessed 18/05/2017]

[22] NIAID Emerging Infectious Diseases/Pathogens. Available at: https://www.niaid.nih.gov/research/emerging-infectious-diseases-pathogens [accessed 18/05/2017]

[23] Syllabus Parasitology module. Available at the USP-CEU website: http://www.uspceu.com/_docs/oferta-academica/fac_far/farmacia/guias-docentes/GD5-a301Parasitologia.pdf [accessed 18/05/2017]

[24] Peña-Fernández A., González-Muñoz MJ., Peña MA. Designing training for teaching environmental toxicology to specialized pharmacists. Currents in Pharmacy Teaching and Learning 2015; 7:864-868. 